\title{
On the Substrate Binding of Linoleate 9-Lipoxygenases
}

\author{
Alexandra-Zoi Andreou • Ellen Hornung • \\ Susan Kunze · Sabine Rosahl · Ivo Feussner
}

Received: 21 July 2008/ Accepted: 30 October 2008/Published online: 27 November 2008

(c) The Author(s) 2008. This article is published with open access at Springerlink.com

\begin{abstract}
Lipoxygenases (LOX; linoleate:oxygen oxidoreductase EC 1.13.11.12) consist of a class of enzymes that catalyze the regio- and stereo specific dioxygenation of polyunsaturated fatty acids. Here we characterize two proteins that belong to the less studied class of 9-LOXs, Solanum tuberosum StLOX1 and Arabidopsis thaliana AtLOX1. The proteins were recombinantly expressed in E. coli and the product specificity of the enzymes was tested against different fatty acid substrates. Both enzymes showed high specificity against all tested $\mathrm{C} 18$ fatty acids and produced (9S)-hydroperoxides. However, incubation of the C20 fatty acid arachidonic acid with AtLOX1 gave a mixture of racemic hydroperoxides. On the other hand, with StLOX1 we observed the formation of a mixture of products among which the (5S)-hydroperoxy eicosatetraenoic acid $(5 S$ $\mathrm{H}(\mathrm{P}) \mathrm{ETE})$ was the most abundant. Esterified fatty acids were no substrates. We used site directed mutagenesis to modify a conserved valine residue in the active site of StLOX1 and examine the importance of space within the active site, which has been shown to play a role in determining the positional specificity. The Val576Phe mutant still catalyzed
\end{abstract}

Sequence data: The nucleotide sequences reported in this paper are annotated in the GenBank/EMBL data bank under the accession numbers Q06327 and S73865.

A.-Z. Andreou · E. Hornung · S. Kunze · I. Feussner $(\bowtie)$

Department of Plant Biochemistry,

Georg-August-University of Göttingen,

Albrecht-von-Haller-Institute of Plant Sciences, Justus-von-Liebig-Weg 11, 37085 Göttingen, Germany

e-mail: ifeussn@gwdg.de

S. Rosahl

Department of Stress and Developmental Biology,

Institute of Plant Biochemistry, Weinberg 3,

06120 Halle, Saale, Germany the formation of (9S)-hydroperoxides with C18 fatty acids, while it exhibited altered specificity against arachidonic acid and produced mainly (11S)-H(P)ETE. These data confirm the model that in case of linoleate 9-LOX binding of the substrate takes place with the carboxyl-group first.

Keywords Lipid peroxidation - Oxylipin formation . Solanum tuberosum

$\begin{array}{ll}\text { Abbreviations } \\ \text { 20:4(n-6) } & \text { Arachidonic acid } \\ \text { 18:3(n-3) } & \alpha \text {-Linolenic acid } \\ \text { CP-HPLC } & \text { Chiral phase-HPLC } \\ \text { GC } & \text { Gas chromatography } \\ \text { 18:3(n-6) } & \gamma \text {-Linolenic acid } \\ \text { HPLC } & \text { High performance liquid chromatography } \\ \text { HETE } & \text { Hydroxy eicosatetraenoic acid } \\ \text { H(P)ETE } & \text { Hydro(pero)xy eicosatetraenoic acid } \\ \text { H(P)ODE } & \text { Hydro(pero)xy octadecadienoic acid } \\ \text { H(P)OTE } & \text { Hydro(pero)xy octadecatrienoic acid } \\ \text { 18:2(n-6) } & \text { Linoleic acid } \\ \text { LOX } & \text { Lipoxygenase(s) } \\ \text { RP-HPLC } & \text { Reversed phase-HPLC } \\ \text { 20:4-PC } & 1,2 \text {-Diarachidonoyl-sn-glycero-3- } \\ & \text { phosphatidylcholine } \\ \text { SP-HPLC } & \text { Straight phase-HPLC } \\ \text { wt } & \text { Wild type }\end{array}$

Introduction

Lipoxygenases (LOX) are a family of non-heme iron containing fatty acid dioxygenases that catalyze the insertion of molecular oxygen into polyunsaturated fatty acids containing a $(1 Z, 4 Z)$-pentadiene system to produce 
hydroperoxides in a regio- and stereo specific manner [1]. One mode of classification of plant LOX is based on the structural features of the proteins and specifically the presence or absence of an amino-terminal plastidic transit peptide, which directs the nascent protein to the plastid. Enzymes are separated into type 1-LOX, which consist of enzymes with high sequence similarity $(\sim 75 \%)$ and no plastidic transit peptide and type 2-LOX which carry a transit peptide sequence and show only moderate sequence similarity $(\sim 35 \%)$ [2]. A second, more common way classifies the enzymes according to the positional specificity of oxygen insertion into C18 fatty acids in 9- and 13LOX [2], while mammalian LOX may be classified according to the oxygenation of $\mathrm{C} 20$ fatty acids in arachidonate 5-, 8-, 9-, 11-, 12- or 15-LOX [1] (Fig. 1).

Two models have been used in order to describe the positional specificity of LOX. Based on data from mammalian LOX, the space-related hypothesis was established, according to which, the fatty acid penetrates the active site with its methyl end first and the depth of the substratebinding pocket determines the site of hydrogen abstraction and position of oxygen insertion $[3,4]$. In the case of plant LOX, the orientation-related hypothesis has been suggested, according to which, in 13-LOX, the substrate enters the active site with the methyl end first. In this class of enzymes, a phenylalanine or a histidine aligning with the so called

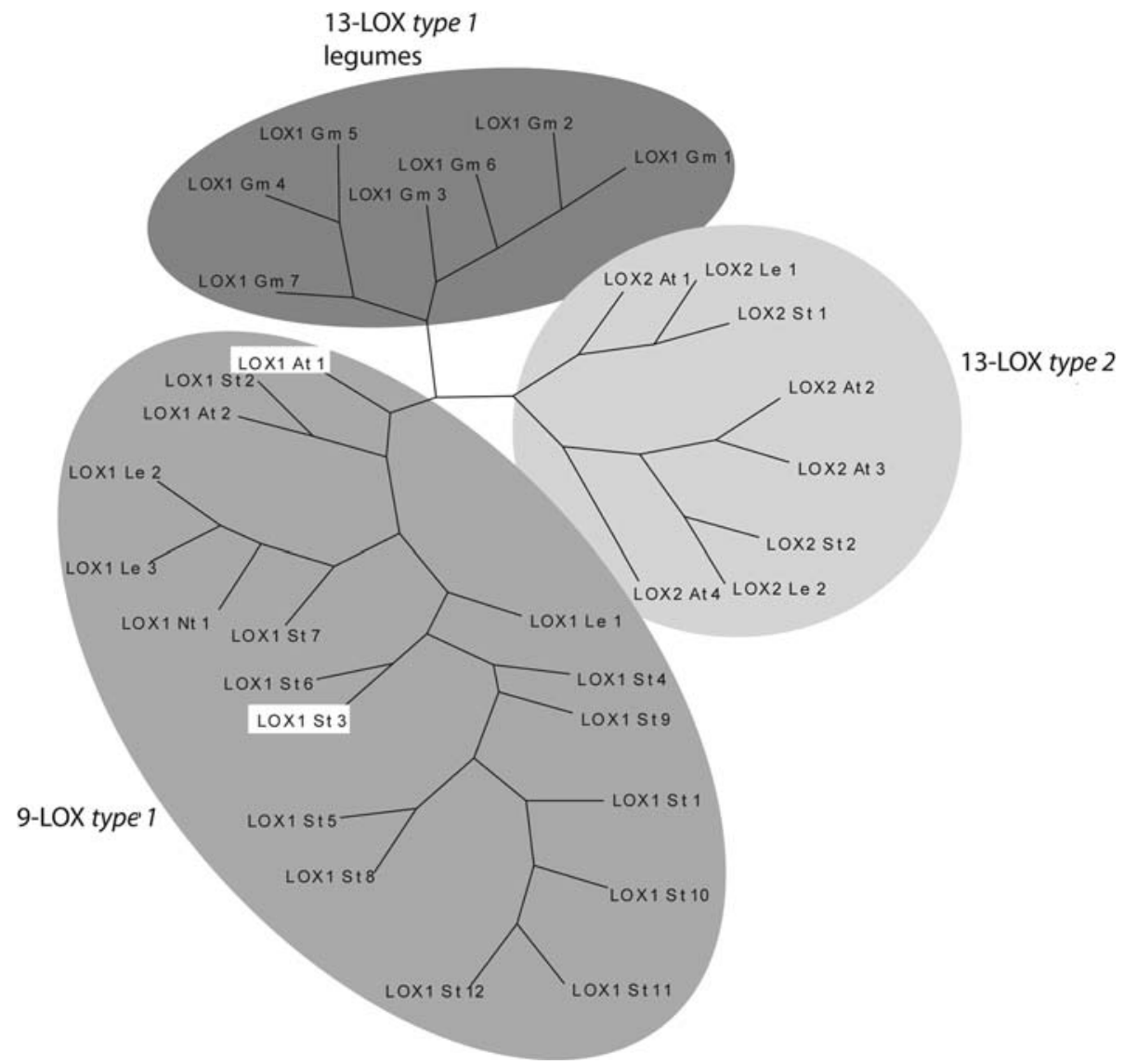

Fig. 1 Phylogenetic analysis of certain plant LOX. The circles indicate the grouping of the enzymes into subcategories. The analysis was performed with PHYLIP 3.5, and the proteins mentioned in the tree refer to the corresponding accession numbers in the gene bank. For clarification, within the tree only sequences from distinct plant species have been included and have been partially renamed according to the nomenclature of [43]: Arabidopsis thaliana: LOX1:At:1 (AtLOX1, Q06327), LOX2:At:1 (AtLOX2, P38418), LOX2:At:2 (AtLOX3, AAF79461), LOX2:At:3 (AtLOX4, AAF21176), LOX1:At:2 (AtLOX5, CAC19365), LOX2:At:4 (AtLOX6, AAG52309); Glycine max: LOX1:Gm:1 (Soybean LOX1, AAA33986), LOX1:Gm:2 (Soybean LOX2, AAA33987), LOX1:Gm:3 (Soybean LOX3, CAA31664), LOX1:Gm:4 (Soybean vlxa, BAA03101), LOX1:Gm:5 (Soybean vlxb, AAB67732),
LOX1:Gm:6 (Soybean vlxc, AAA96817), LOX1:Gm:7 (Soybean vlxd, S13381); Lycopersicum esculentum: LOX1:Le:1 (tom-LOXA, P38415), LOX1:Le:2 (tomLOXB, P38416), LOX1:Le:3 (tomLOXtox, AAG21691), LOX2:Le:1 (tomLOXC, AAB65766), LOX2:Le:2 (tomLOXD, AAB65767); Nicotiana tabacum: LOX1:Nt:1 (NtLOX, S57964); Solanum tuberosum: LOX1:St:1 (SOLTULOX1, S44940), LOX1:St:2 (STLOX, AAD09202), LOX1:St:3 (StLOX1, P37831), LOX1:St:4 (CAA64766), LOX1:St:5 (CAA64765), LOX1:St:6 (POTLX-2, AAB67860) LOX1:St:7 (POTLX-3, AAB67865), LOX1:St:8 (POTLX-1, AAB67858), LOX1:St:9 (AAD04258), LOX1:St:10 (pLOX2, AAB81595), LOX1:St:11 (pLOX1, AAB81594), LOX1:St:12 (CAB65460), LOX2:St:1 (StLOXH1, CAA65268), LOX2:St:2 (St-LOXH3, CAA65269) 
"Sloane determinants" controls the depth of the enzyme active site (Table 1). In 9-LOX the amino acid aligning with this position is usually a less space-filling valine residue. It is is suggested that the presence of the smaller amino acid demasks a positively charged arginine residue, the so-called "Hornung determinant", at the bottom of the substrate pocket, which can stabilize an insertion of the substrate with the carboxylic group first in the active site pocket leading to a preferable oxygen insertion in position 9 [5].

The molecular determinants of stereo specificity of the LOX reaction have been the focus of a number of recent studies [6]. These studies have highlighted the importance of a single amino acid residue, which is a conserved alanine in $S$-specific LOX and a glycine in the case of $R$-LOX. Conversion of the glycine of an $R$-LOX to an alanine and vice versa has been successful in partially switching the position of oxygenation and chirality of the product of the enzymatic reaction, for example converting a (13S)- into a (9R)-LOX enzyme [7]. Based on recent mutagenesis data obtained for a LOX from Anabeana sp. PCC 7120, the existing model for stereo control of the LOX reaction may be expanded for enzymes that seem to have in general a bulkier amino acid in $S$-LOX at this position that controls stereospecificity [8, 9].

Plant LOX are involved in a variety of processes of plant growth and development, e.g. through the mobilization of storage lipids during germination [10]. Furthermore, a class of these enzymes is thought to function as nitrogen storage proteins during vegetative growth [11]. Another important function of LOX secondary products, such as jasmonic acid, is their crucial role in defense responses against wounding and pathogen attack [12].

In most plant species, LOX are encoded by gene families, composed of a number of isozymes, differing in the position of substrate oxygenation, substrate specificity and kinetic parameters [13]. These enzymes are also often spatially and temporarily differentially expressed [14].

A relatively simple LOX family exists in Arabidopsis thaliana. It contains six putative lipoxygenase sequences
(AtLOX1-6) [2]. So far, physiological functions of four of these enzymes, AtLOX1 (lox 1:At:1), AtLOX2 (lox2:At:1) AtLOX3 (lox2:At:2) and AtLOX4 (lox2:At:3) have been described, but biochemical characterization has still to take place. AtLOX1 has been previously described to be expressed in various organs of the plant and upregulated in response to pathogen attack [15], while AtLOX2 is expressed upon wounding [16]. AtLOX3 and AtLOX4 have been discussed to be involved in leaf senescence [17]. Based on sequence determinants and homology AtLOX1 (lox 1:At:1) is postulated to harbor 9-LOX activity, whereas AtLOX2-4 may harbor 13-LOX activity (Table 1; Fig. 1).

In potato, a number of LOX cDNAs have been isolated from tubers, roots and leaves [18-24]. LOX belong to the group of genes that have been shown to be expressed early during potato tuber formation [22, 24], and LOX secondary products, such as jasmonic acid and its derivative tuberonic acid, have been shown to induce tuberization in vitro [25, 26]. Interestingly, the most abundant LOX activity detected was of 9-positional specificity and this activity increases upon wounding [27].

Our studies focus on two type 1-LOX, StLOX1 (lox 1:St:3) and AtLOX1. StLOX1 is a LOX from potato tubers [19], which has a $\mathrm{pH}$-optimum between $\mathrm{pH} 5.5$ and 7.5, uses linoleic [18:2(n-6)] and $\alpha$-linolenic acid [18:3(n-3)] preferentially, but can also use arachidonic acid [20:4(n-6)] as substrate. The later is converted primarily to 5-H(P)ETE. The specificity of this reaction is however lower than in the case of mammalian arachidonate 5-LOX [28]. AtLOX1 also belongs to the same class of enzymes, but its product specificity with $\mathrm{C} 18$ and $\mathrm{C} 20$ fatty acids has yet to be investigated. A comparison of the determinants of positional specificity of characterized LOX enzymes with lox 1:St:3 indicates that both enzymes carry the typical determinants of 9-LOX, namely a threonine and a valine (Table 1). In order to obtain a better insight into the factors determining the positional specificity of 9-LOX, we overexpressed the recombinant enzymes, investigated the enzymatic activity
Table 1 Alignment of amino acid residues possibly determining the positional specificity of plant and moss LOX

\begin{tabular}{llll}
\hline Enzyme & Acc. no. & $\begin{array}{l}\text { Position of amino } \\
\text { acid residues }\end{array}$ & $\begin{array}{l}\text { Amino acid } \\
\text { residues }\end{array}$ \\
\hline $\begin{array}{l}\text { 9-LOX } \\
\text { Solanum tuberosum StLOX1 }\end{array}$ & P37831 & $575 / 576$ & Thr/Val \\
Arabidopsis thaliana AtLOX1 & Q06327 & $576 / 577$ & Thr/Val \\
Hordeum vulgare LOX-A & L35931 & $574 / 575$ & Thr/Val \\
Cucumis sativus LOX1:Cs4 & CAB83038 & $594 / 595$ & Thr/Val \\
13-LOX & & & \\
Glycine max sLOX-1 & P08170 & $556 / 557$ & Thr/Phe \\
Oryza sativa LOX-1 & BAA03102 & $678 / 679$ & Ser/Phe \\
Arabidopsis thaliana AtLOX2 & P38418 & $611 / 612$ & Cys/Phe \\
Physcomitrella patens PpLOX & CAE47464 & $654 / 655$ & His/Phe \\
\hline
\end{tabular}


with different substrates and generated and characterized a mutant of potato tuber LOX, where the typical Val determinant of 9-LOX has been exchanged for a Phe, which alters the specificity of the enzyme against arachidonic acid.

\section{Experimental Procedures}

The chemicals used were from the following sources: standards of chiral and racemic hydroxy fatty acids from Cayman Chem. (Ann Arbor, MI, USA), trilinolein and triarachidonin from Sigma (Deisenhofen, Germany), 1,2diarachidonoyl-sn-glycero-3-phosphatidylcholine from Larodan (Malmo, Sweden); methanol, hexane, 2-propanol (all HPLC grade) from Baker (Griesheim, Germany). Restriction enzymes were purchased from MBI Fermentas (St Leon-Rot, Germany).

\section{Site-Directed Mutagenesis}

As a template for site directed mutagenesis plasmid pETstLOX1 was used, consisting of the potato tuber LOX [19] in pET3b (Novagen, Germany). Mutagenesis was carried out by using the QuikChange site-directed mutagenesis kit (Stratagene, Heidelberg, Germany). The oligonucleotides used for mutagenesis contained apart from the appropriate base changes additional conservative base exchanges which either created new restriction sites or deleted existing ones for simplified identification of mutants. The following oligonucleotides were used: stLOX-V576Fa 5'-GGTGGGGTTCTTGAGAGTACATTCTTTCCTTCGA AATTTGCCATGGAAATGTCAG- $3^{\prime} ; \quad$ stLOX-V576Fb 5'-CGTACATTTCCATGGCAAATTTCGAAGGAAAGA ATGTACTCTCAAGAACCCCACC-3'. In addition all mutations were sequenced and at least three different bacterial colonies were expressed and used for analysis of enzymatic parameters.

\section{Protein Expression and LOX Activity Assay}

For expression analysis StLOX1 containing plasmids and pBS-SK-AtLOX1 (ABRC clone H3C1T7) were transferred into E. coli strain BL21(De3) Star (Novagen, Germany). Thirty millilitre cultures were grown at $37{ }^{\circ} \mathrm{C}$ to an $\mathrm{OD}_{600}$ of 0.6 , induced with $1 \mathrm{mM}$ IPTG and cultivated further at $16^{\circ} \mathrm{C}$ for $48 \mathrm{~h}$. Cells were harvested by centrifugation at $4{ }^{\circ} \mathrm{C}$ at $4,000 \times g$ resuspended in $5 \mathrm{ml}$ lysis buffer $[50 \mathrm{mM}$ Tris $-\mathrm{HCl}$, $\mathrm{pH}$ 7, $300 \mathrm{mM} \mathrm{NaCl}, 10 \%$ (v/v) glycerol, $0.1 \%$ (v/v) Tween 20] and lysed by sonification. Nine-hundred microliters of lysate was incubated with $250 \mu \mathrm{g}$ of the respective fatty acids for $30 \mathrm{~min}$ at RT, the resulting hydroperoxides were reduced with $2.5 \mathrm{mg}$ tin(II) chloride in methanol, acidified with glacial acetic acid to $\mathrm{pH} 3$ and lipids were extracted by the method of Bligh and Dyer [29]. Analysis of the fatty acids was performed on a HPLC (see below).

The activity of StLOX1 with trilinolein or triarachidonin was measured by incubating $900 \mu \mathrm{l}$ lysate with $1 \mathrm{mg}$ of the respective substrate under constant shaking for $30 \mathrm{~min}$ at room temperature. In order to test activity against 20:4-PC, $0.6 \mathrm{mg}$ of substrate were incubated with the enzyme in $5 \mathrm{ml}$ buffer (50 mM Tris $\mathrm{pH} \mathrm{7,} 4 \mathrm{mM}$ sodium deoxycholate) under constant stirring in RT. In both cases reduction of the hydroperoxides was carried out as described above. The lipid bound fatty acids were then converted to the corresponding methyl esters by adding $500 \mu \mathrm{l}$ of $1 \%$ sodium methoxide solution in methanol to the dried samples after chloroform evaporation and shaken for $20 \mathrm{~min}$ at room temperature. Five-hundred microliters of $6 \mathrm{M} \mathrm{NaCl}$ was added to the reaction and the methyl esters were then extracted twice with $750 \mu \mathrm{l}$ hexane. The solvent was removed by evaporation under a stream of nitrogen and the sample was dissolved in $80 \mu \mathrm{l}$ of methanol/water/acetic acid (85:15:0.1, v/v/v).

\section{Analytics}

High performance liquid chromatography (HPLC) analysis was carried out on an Agilent (Waldbronn, Germany) 1100 HPLC system coupled to a diode array detector. Reversed phase-HPLC (RP-HPLC) of the free fatty acid derivatives was carried out on a Nucleosil C-18 column (MachereyNagel, Düren, FRG; $250 \times 2 \mathrm{~mm}, 5 \mu \mathrm{m}$ particle size) with a solvent system of methanol/water/acetic acid (90/10/0.1, $\mathrm{v} / \mathrm{v} / \mathrm{v}$ ) and a flow rate of $0.18 \mathrm{ml} / \mathrm{min}$. The absorbance at $234 \mathrm{~nm}$ (conjugated diene system of the hydroxy fatty acids) and $210 \mathrm{~nm}$ (polyenoic fatty acids) were recorded simultaneously. Straight phase-HPLC (SP-HPLC) of hydroxy fatty acid isomers was carried out on a Phenomenex Luna Silica column (Aschaffenburg, Germany; $50 \times 4.6 \mathrm{~mm}, 3 \mu \mathrm{m}$ particle size) with a solvent system of $n$-hexane/2-propanol/trifluoroacetic acid (100/1/0.1, v/v/v) and a flow rate of $0.2 \mathrm{ml} / \mathrm{min}$. The enantiomer composition of the hydroxy fatty acids (C18) was analyzed by chiral phase-HPLC (CP-HPLC) on a Chiralcel OD-H column (Diacel Chem. Industries, distributed by Merck, Darmstadt, Germany; $150 \times 2.1 \mathrm{~mm}, 5 \mu \mathrm{m}$ particle size) with a solvent system of hexane/2-propanol/trifluoroacetic acid (100/ $5 / 0.1, \mathrm{v} / \mathrm{v} / \mathrm{v}$ ) and a flow rate of $0.1 \mathrm{ml} / \mathrm{min}$. For separation of chiral isomers of 12, 15, 11 and 8 hydroxy eicosatetraenoic acid (HETE) a solvent system of hexane/2-propanol/ trifluoroacetic acid (100/2/0.1, v/v/v) was used. 5-HETE stereo isomers were analyzed using a solvent system of $n$-hexane/2-propanol/trifluoroacetic acid (100/1/0.1 v/v/v) at a flow rate of $0.2 \mathrm{ml} / \mathrm{min}$. Methyl esters were separated by RP-HPLC with a solvent system of methanol/water/ acetic acid $(75: 25: 0.1, \mathrm{v} / \mathrm{v} / \mathrm{v})$ at a flow rate of $0.18 \mathrm{ml} / \mathrm{min}$. 
SP-HPLC analysis was carried out with a solvent system hexane: 2-propanol: trifluoro acetic acid (100:1:0.1, v/v/v) at a flow rate of $0.1 \mathrm{ml} / \mathrm{min}$.

\section{Phylogenetic Analysis}

Phylogenetic tree analysis was performed on deduced amino acid sequences of selected LOX by using PHYLIP3.5 (Department of Genome Sciences, University of Washington) [30] using default parameters.

\section{Results}

Our studies aim was to analyze the substrate specificity of two putative 9-LOX, StLOX1, a LOX from potato tubers [19] and AtLOX1 (lox1:At:1), a LOX expressed in Arabidopsis leaves, roots inflorescences and young seedlings [31]. In order to characterize their regio- and stereospecificity, we overexpressed the enzymes in $E$. coli and investigated the enzymatic activity with different substrates. Moreover we generated and characterized a mutant that alters the specificity of StLOX1.
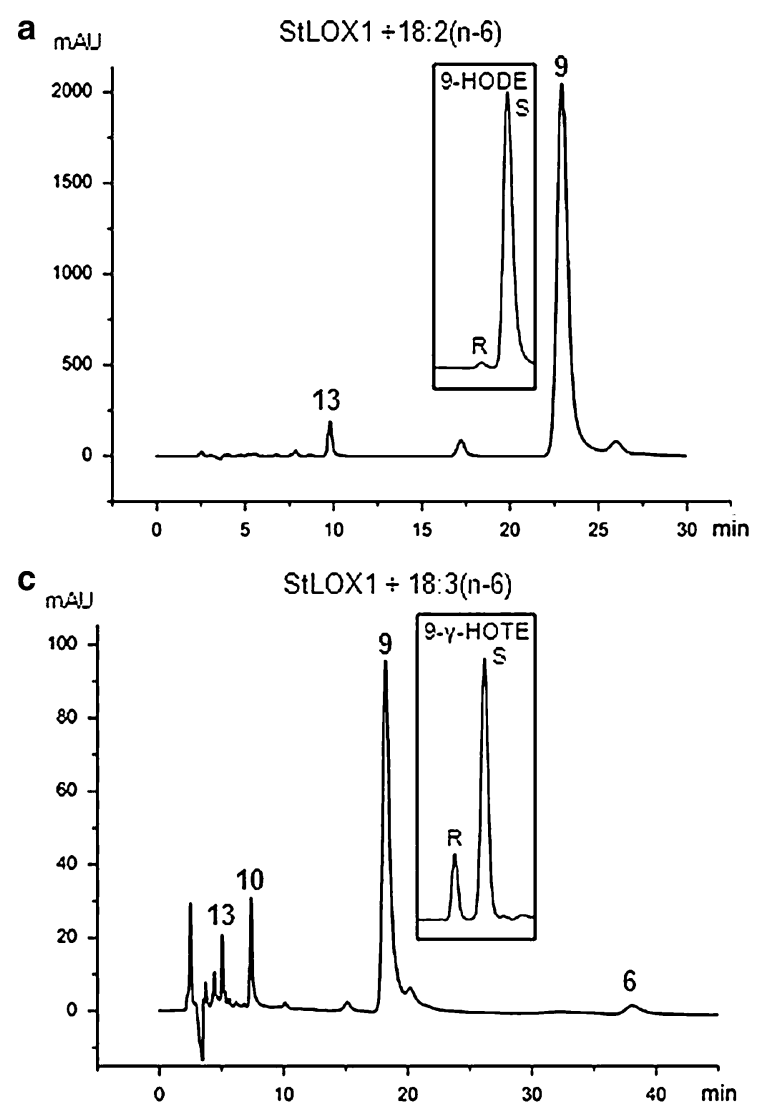

Fig. 2 SP-HPLC analysis of products formed by wt StLOX1 incubated with a 18:2(n-6), b 18:3(n-3), c 18:3(n-6) and d 20:4(n6) (here in their reduced form). The separation of the enantiomers of

\section{Product Analysis of StLOX1 and AtLOX1}

For product analysis, crude cell extracts of $E$. coli expressing StLOX1 were incubated with $250 \mu \mathrm{g}$ of 18:2(n6), 18:3(n-3), $\gamma$-linolenic acid [18:3(n-6)], and 20:4(n-6), respectively, and the reduced products were analyzed by HPLC. E. coli cell extracts expressing AtLOX1 were likewise incubated with 18:2(n-6), 18:3(n-3) and 20:4(n-6) and products were analyzed. When 18:2(n-6) was used as substrate StLOX1 produced 9-hydro(pero)xy octadecadienoic acid [9-H(P)ODE, 98\%] with almost exclusively $S$ stereo configuration (Fig. 2a). Racemic 13-H(P)ODE was only a minor byproduct. Correspondingly, 94\% 9H(P)ODE of primarily $S$ configuration was the main product of 18:2(n-6) incubation with AtLOX1 (Fig. 3a; Table 2). 18:3(n-3) is converted in a comparable manner to 9-hydro(pero)xy octadecatrienoic acid [9-H(P)OTE; 94\%], mainly of the $S$ enantiomer by both enzymes (Figs. 2b, 3b; Table 2). Racemic 12-, 13- and 16-H(P)OTE were only minor byproducts. Similarly, upon incubation of StLOX1 with $18: 3(\mathrm{n}-6)$, the main product was $(9 S)-\gamma-\mathrm{H}(\mathrm{P}) \mathrm{OTE}$ (72\%), with racemic 6-, 10- and 13- $\gamma-\mathrm{H}(\mathrm{P}) \mathrm{OTE}$ as secondary products (Fig. 2c). The two enzymes, however,

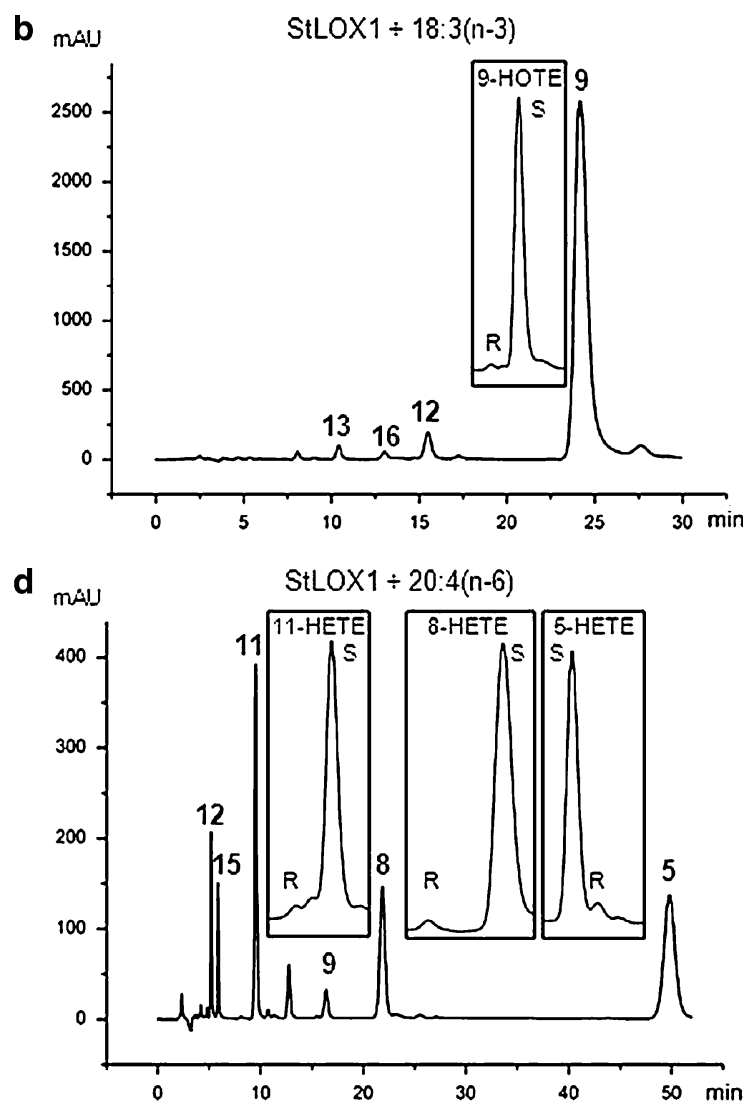

chiral products by CP-HPLC is shown in the insets. Enzyme preparations of StLOX1 were incubated with their respective substrates at $\mathrm{pH} 7$ 


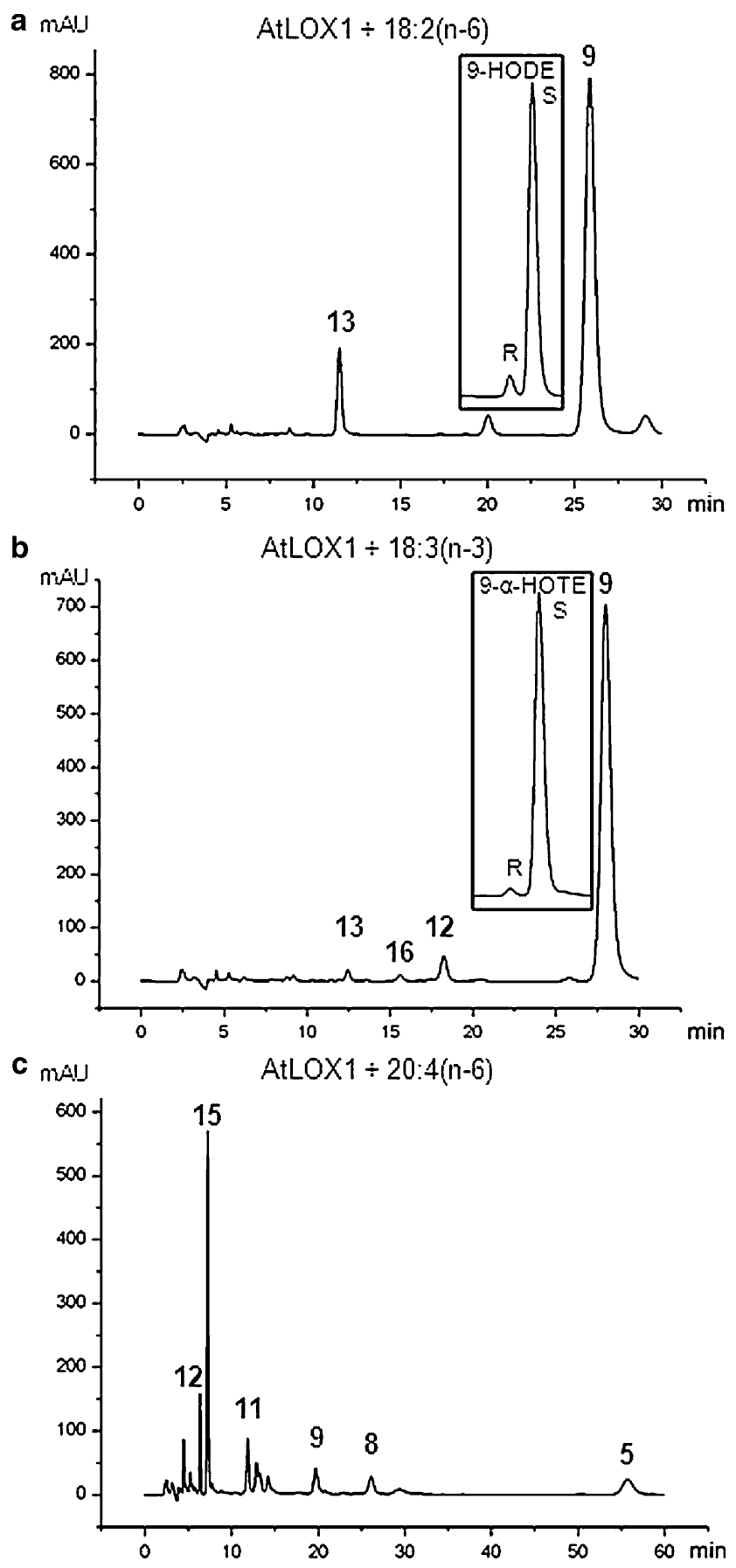

Fig. 3 SP-HPLC analysis of products formed by wt AtLOX1 incubated with a 18:2(n-6), b 18:3(n-3) and c 20:4(n-6) (here in their reduced form). The separation of the enantiomers of chiral products by CP-HPLC is shown in the insets. Enzyme preparations of AtLOX1 were incubated with their respective substrates at $\mathrm{pH} 7$

exhibited different product specificity when 20:4(n-6) was used as substrate. AtLOX1 exhibited notably decreased enzymatic activity against 20:4(n-6) in comparison to the tested C18 substrates as estimated by RP-HPLC analysis of products formed when a mixture of substrates was applied (data not shown). In addition the $\mathrm{C} 20$ fatty acid was
Table 2 Products formed from the reaction of wt AtLOX1 with various fatty acid substrates

\begin{tabular}{llll}
\hline Substrate & Products & Ratio $(\%)$ & $S$ enantiomer $(\%)$ \\
\hline 18:2(n-6) & 13/9-HOD & $10: 90$ & $49: 94$ \\
18:3(n-3) & 13/16/12/9-HOT & $1: 1: 4: 94$ & $49: 51: 47: 98$ \\
20:4(n-6) & $\begin{array}{c}\text { 15/12/11/9/8/5- } \\
\text { HETE }\end{array}$ & $44: 11: 13: 9: 9: 14$ & $50: 53: 53: 50: 48: N A$ \\
& & \\
\hline
\end{tabular}

$N A$ not analyzed

converted into a mixture of racemic products of comparable amounts (Fig 3c; Table 2). On the other hand, StLOX1 converted 20:4(n-6) into a mixture of three major products, 5-H(P)ETE (43\%), 11-H(P)ETE $(26 \%)$ and 8-H(P)ETE (23\%). Chiral analysis of the fatty acid hydroperoxides by CP-HPLC revealed that the main products, 5-, 11- and 8$\mathrm{H}(\mathrm{P})$ ETE are primarily of the typical $S$ configuration. Minor amounts of racemic 12-H(P)ETE, 15-H(P)ETE and 9-H(P)ETE could also be detected (Fig 2d).

Additionally, we tested the activity of StLOX1 against a number of esterified fatty acids as substrates. Trilinolein and triarachidonin were used as substrates under the conditions described for the cucumber lipid body LOX, CslbLOX [5], while 1,2-diarachidonoyl-sn-glycero-3phosphatidylcholine, as has been described for other LOX enzymes $[8,9]$. We could not observe activity against any of the substrates, which suggests that binding of the substrate takes place with the carboxyl-group first.

Mutagenesis of Positional Determinants Identified from Other LOX Isoforms

Mutagenesis studies on LOX identified that among plant enzymes, one conserved amino acid, bulky in the case of 13-LOX and smaller in the case of 9-LOX (Table 1), plays a crucial role in determining the positional specificity of the product. In the case of StLOX1, the amino acid aligning with this residue is the widely conserved among 9-LOX valine (V576). In order to investigate the influence of these residues on StLOX1, we introduced the more space filling phenylalanine at this position. This resulted in a pair of residues, similar to the ones found in the active site of sLOX-1, a 13-LOX from soybean (Table 1). Subsequently, we tested the specificity of the mutant obtained with the same substrates as the wt. 18:2(n-6), 18:3(n-3) and 18:3(n6) were converted, in a comparable manner as the wt, primarily into their respective 9-hydroperoxides (data not shown). Interestingly, conversion of valine to a phenylalanine resulted in a shift of the major oxygenation product specificity from 5-H(P)ETE in the wt enzyme to 11H(P)ETE (55\%) in the mutant. Significant amounts of 8$\mathrm{H}(\mathrm{P}) \mathrm{ETE}$, comparable to the wt, were also formed (22\%), while 12-H(P)ETE, 15-H(P)ETE, 5-H(P)ETE were only 
Table 3 Products formed from the reaction of wt StLOX1 and V576F mutant with 20:4(n-6)

$N A$ not analyzed

\begin{tabular}{|c|c|c|c|c|c|}
\hline \multirow[b]{2}{*}{ Enzyme } & \multicolumn{5}{|c|}{ Positional isomers obtained with arachidonic acid ( $S$ enantiomer) $(\%)$} \\
\hline & 12 & 15 & 11 & 8 & 5 \\
\hline Wild type StLOX1 & $6(45)$ & $4(56)$ & $26(99)$ & $23(80)$ & $41(97)$ \\
\hline V576F & $4(57)$ & $9(53)$ & $55(100)$ & $22(92)$ & 10 (NA) \\
\hline
\end{tabular}

present in smaller amounts $(\leq 10 \%$; Table 3$)$. 9-H(P)ETE could only be detected in traces. Chiral analysis of the hydroperoxides revealed chirality of 11-H(P)ETE and 8-H(P)ETE in $S$ configuration while 15-H(P)ETE and 12-H(P)ETE were racemic (Fig. 4) The amounts of 5-H(P)ETE and 9H(P)ETE were too low for CP analysis.

\section{Discussion}

In this study we aimed to characterize the product specificity of two predicted 9-LOX, a LOX from potato tubers

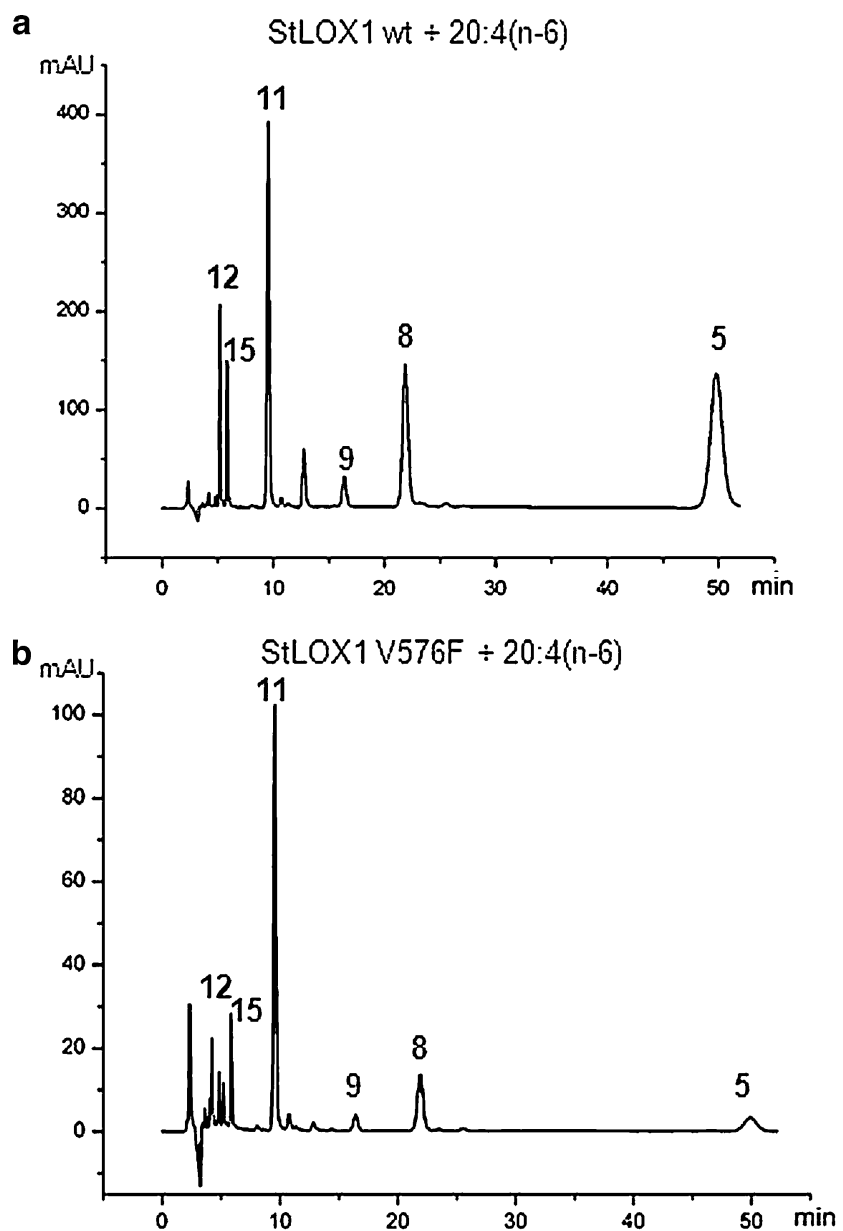

Fig. 4 SP-HPLC analysis of products formed by $\mathbf{a}$ wt StLOX1 and $\mathbf{b}$ V576F "Sloane" mutant enzyme with 20:4(n-6) as substrate (here in their reduced form for SP-HPLC analysis). Enzyme preparations of wt and Val $\rightarrow$ Phe (V576F) were incubated with 20:4(n-6) at $\mathrm{pH} 7$ and a LOX from Arabidopsis. For this purpose, we analyzed the LOX reaction products after incubation of the recombinantly expressed proteins with different fatty acid substrates. We also performed mutagenesis studies on StLOX1 and altered one of the residues, which has been reported to play a role in determining the positional specificity of LOX.

StLOX1 could convert all tested C18 fatty acids, 18:2(n-6), 18:3(n-3) and 18:3(n-6), to the corresponding (9S)-hydroperoxides with high specificity. Similar results have been previously observed for other analyzed potato tuber LOX [24, 32]. AtLOX1 showed comparably high specificity against the C18 fatty acids 18:2(n-6) and 18:3(n-3). These 9-hydroperoxides can be further metabolized by enzymes, such as the hydroperoxide reductase, divinyl ether synthase and epoxy alcohol synthase to yield epoxy alcohols and divinyl ethers among other products [33]. The function of the 9-LOX-derived products is still unclear, but they have been implicated in responses against biotic and abiotic stress. One possibility is that they confer resistance against pathogen attack. For example, LOX pathway products accumulate in potato leaves when they are under $P$. infestans infection [34]. Additionally, upregulation of 9-LOX transcripts has been observed upon wounding [19]. Similarly, in Arabidopsis, AtLOX1 has been reported to be induced by the stressrelated hormones abscisic acid and methyl jasmonate and pathogen attack [31] Another postulated function of 9-hydroperoxide derivatives is in potato that they may play a role in tuber growth regulation [35].

Additionally, we analyzed the metabolism of 20:4(n-6) by AtLOX1 and StLOX1. AtLOX1 did not demonstrate any specificity against the $\mathrm{C} 20$ fatty acid, since a mixture of racemic products was obtained. LOX often show decreased specificity when the protein in the reaction is in limiting amounts. However, we incubated the protein with a mixture of substrates and C18 fatty acids were converted into chiral products while $\mathrm{C} 20$ fatty acids were not. Therefore, this explanation seems unlikely. There are no previous reports on the product specificity of Arabidopsis lipoxygenases with 20:4(n-6), so it appears that this fatty acid may not be a substrate for AtLOX1. On the other hand, potato tuber LOX have been studied for many years as a model for 5-LOX activity [36, 37]. In the case of StLOX1, 5-H(P)ETE was the main reaction product, while 11-H(P)ETE and 8-H(P)ETE were also produced in 
significant amounts. For 5-H(P)ETE production a hydrogen atom is abstracted from the C7 carbon atom of 20:4(n-6). The resulting carbon-centered radical intermediate undergoes rearrangement in the (n-2) position and in a final step, oxygen is inserted at C5. Similarly, 11-H(P)ETE and 8-H(P)ETE are the result of hydrogen abstraction at C13 and $\mathrm{C} 10$, respectively and a subsequent introduction of oxygen in the (n-2) position. The relatively low specificity of the first step of the LOX reaction suggests that binding of the substrate in the active site is more flexible in comparison to C18 fatty acids, allowing in the case of 20:4(n-6) abstraction of hydrogen atoms from different carbon atoms in comparison to $\mathrm{C} 18$ substrates, where in all cases the hydrogen atom of $\mathrm{C} 11$ is preferentially abstracted. The percentages of product formation are similar to the ones reported for the tomato enzyme [38]. The relative amount of 5-H(P)ETE is smaller though then the ones reported from a previously characterized potato tuber LOX [39] and a barley isozyme [40]. Chiral phase analysis showed that the hydroperoxides were of $S$-configuration. Similar results have been reported from other analyses of 5-hydroperoxides from plant enzymes [38, 40].

Regarding the substrate binding in the active site of StLOX1, the fact that no reaction products could be observed with trilinolein and triarachidonin or 1,2-diarachidonoyl-sn-glycero-3-phosphatidylcholine supports that the fatty acids can only bind with their carboxyl group first. This is a similar mode of binding as has been previously been suggested for 9-LOX [41, 42].

In addition the product specificity of a StLOX1 mutant in which a valine residue aligning with one of the "Sloane" determinants was exchanged against a bulkier phenylalanine was examined. Remarkably, this exchange did not influence the product specificity of the enzyme, when C18 fatty acids were used as substrates. According to the existing models, the residue in question is in close proximity to an arginine residue positioned on the bottom of the active site pocket. In 13-LOX the phenylalanine is thought to shield the positive charge of this arginine and lead to a preferential entry of the fatty acid with the methyl group first, leading to oxygenation at position C13 [5]. However, our data on StLOX1 suggest that the valine to phenylalanine exchange may not be sufficient to change the product specificity of $\mathrm{C} 18$ fatty acid conversion for this enzyme and therefore does not alter the favored substrate orientation in the active site of the enzyme. When the mutant enzyme, however, was incubated with 20:4(n-6) we observed an altered specificity, namely 11-H(P)ETE was the main product. This change suggests that inserting a bulky amino acid at the bottom of the active site pocket influences at least the alignment of the bulkier fatty acid 20:4(n-6) in the active site, although the substrate orientation is not altered either. In summary our data support the previously suggested active site model that in case of 9LOX the substrate binds with its carboxyl-group first that seem to be the natural substrates of these enzymes.

Acknowledgments The authors are grateful to Dr. Cornelia Göbel, Göttingen, for her expert technical support. A.A. is supported by the International master/Ph.D. program Molecular Biology and the Max Planck Research School Molecular Biology (Göttingen). The project is funded by IRTG 1422 Metal Sites in Biomolecules: Structures, Regulation and Mechanisms. We thank the ABRC for providing with the cDNA encoding AtLOX1.

Open Access This article is distributed under the terms of the Creative Commons Attribution Noncommercial License which permits any noncommercial use, distribution, and reproduction in any medium, provided the original author(s) and source are credited.

\section{References}

1. Schneider C, Pratt DA, Porter NA, Brash AR (2007) Control of oxygenation in lipoxygenase and cyclooxygenase catalysis. Chem Biol 14:473-488

2. Liavonchanka A, Feussner I (2006) Lipoxygenases: occurrence, functions and catalysis. J Plant Physiol 163:348-357

3. Browner MF, Gillmor SA, Fletterick R (1998) Burying a charge. Nat Struct Biol 5:179

4. Sloane DL, Leung R, Craik CS, Sigal E (1991) A primary determinant for lipoxygenase positional specificity. Nature 354:149-152

5. Hornung E, Walther M, Kühn H, Feussner I (1999) Conversion of cucumber linoleate 13-lipoxygenase to a 9-lipoxygenating species by site-directed mutagenesis. Proc Natl Acad Sci USA 96:4192-4197

6. Coffa G, Schneider C, Brash AR (2005) A comprehensive model of positional and stereo control in lipoxygenases. Biochem Biophys Res Commun 338:87-92

7. Coffa G, Brash AR (2004) A single active site residue directs oxygenation stereospecificity in lipoxygenases: stereocontrol is linked to the position of oxygenation. Proc Natl Acad Sci USA 101:15579-15584

8. Andreou A-Z, Vanko M, Bezakova L, Feussner I (2008) Properties of a mini $9 R$-lipoxygenase from Nostoc sp. PCC 7120 and its mutant forms. Phytochemistry 69:1832-1837

9. Zheng Y, Boeglin WE, Schneider C, Brash AR (2008) A 49-kDa mini-lipoxygenase from Anabaena sp. PCC 7120 retains catalytically complete functionality. J Biol Chem 283:5138-5147

10. Feussner I, Kühn H, Wasternack C (2001) The lipoxygenase dependent degradation of storage lipids. Trends Plant Sci 6:268273

11. Fischer AM, Dubbs WE, Baker RA, Fuller MA, Stephenson LC, Grimes HD (1999) Protein dynamics, activity and cellular localization of soybean lipoxygenases indicate distinct functional roles for individual isoforms. Plant J 19:543-554

12. Howe GA, Jander G (2008) Plant immunity to insect herbivores. Annu Rev Plant Biol 59:41-66

13. Feussner I, Wasternack C (2002) The lipoxygenase pathway. Annu Rev Plant Biol 53:275-297

14. Siedow JN (1991) Plant lipoxygenase-structure and function. Ann Rev Plant Physiol Plant Mol Biol 42:145-188

15. Bell E, Mullet JE (1993) Characterization of an Arabidopsislipoxygenase gene responsive to methyl jasmonate and wounding. Plant Physiol 103:1133-1137 
16. Bell E, Creelman RA, Mullet JE (1995) A chloroplast lipoxygenase is required for wound-induced jasmonic acid accumulation in Arabidopsis. Proc Natl Acad Sci USA 92:8675-8679

17. He Y, Fukushige H, Hildebrand DF, Gan S (2002) Evidence supporting a role of jasmonic acid in Arabidopsis leaf senescence. Plant Physiol 128:876-884

18. Casey R (1995) Sequence of a cDNA clone encoding a potato (Solanum tuberosum) tuber lipoxygenase. Plant Physiol 107:265266

19. Geerts A, Feltkamp D, Rosahl S (1994) Expression of lipoxygenase in wounded tubers of Solanum tuberosum L. Plant Physiol 105:269-277

20. Hughes RK, West SI, Hornostaj AR, Lawson DM, Fairhurst SA, Sanchez RO, Hough P, Robinson BH, Casey R (2001) Probing a novel potato lipoxygenase with dual positional specificity reveals primary determinants of substrate binding and requirements for a surface hydrophobic loop and has implications for the role of lipoxygenases in tubers. Biochem J 353:345-355

21. Kolomiets MV, Chen H, Gladon RJ, Braun EJ, Hannapel DJ (2000) A leaf lipoxygenase of potato induced specifically by pathogen infection. Plant Physiol 124:1121-1130

22. Kolomiets MV, Hannapel DJ, Gladon RJ (1996) Potato lipoxygenase genes expressed during the early stages of tuberization. Plant Physiol 112:446

23. Kolomiets MV, Hannapel DJ, Gladon RJ (1996) Nucleotide sequence of a cDNA clone for a lipoxygenase from abscisic acidtreated potato leaves. Plant Physiol 112:446

24. Royo J, Vancanneyt G, Perez AG, Sanz C, Störmann K, Rosahl S, Sanchez-Serrano JJ (1996) Characterization of three potato lipoxygenases with distinct enzymatic activities and different organspecific and wound-regulated expression patterns. J Biol Chem 271:21012-21019

25. Pelacho AM, Mingo-Castel AM (1991) Jasmonic acid induces tuberization of potato stolons cultured in vitro. Plant Physiol 97:1253-1255

26. Koda Y, Kikuta Y, Tazaki H, Tsujino Y, Sakamura S, Yoshihara $\mathrm{T}$ (1991) Potato tuber-inducing activities of jasmonic acid and related compounds. Phytochemistry 30:1435-1438

27. Galliard T (1980) Lipid oxidation and flavor biogenesis in edible plants. J Am Oil Chem Soc 57:A164-A165

28. Feussner I, Kühn H (2000) Application of lipoxygenases and related enzymes for the preparation of oxygenated lipids. In: Bornscheuer UT (ed) Enzymes in lipid modification. Wiley$\mathrm{VCH}$, Weinheim

29. Bligh EG, Dyer WJ (1959) A rapid method of total lipid extraction and purification. Can J Biochem Physiol 37:911-917
30. Felsenstein J, Churchill GA (1996) A hidden Markov model approach to variation among sites in rate of evolution. Mol Biol Evol 13:93-104

31. Melan MA, Dong XN, Endara ME, Davis KR, Ausubel FM, Peterman TK (1993) An Arabidopsis thaliana lipoxygenase gene can be induced by pathogens, abscisic acid, and methyl jasmonate. Plant Physiol 101:441-450

32. Chen XY, Reddanna P, Reddy GR, Kidd R, Hildenbrandt G, Reddy CC (1998) Expression, purification, and characterization of a recombinant 5-lipoxygenase from potato tuber. Biochem Biophys Res Commun 243:438-443

33. Stumpe M, Feussner I (2006) Formation of oxylipins by CYP74 enzymes. Phytochemistry Rev 5:347-357

34. Weber H, Chetelat A, Caldelari D, Farmer EE (1999) Divinyl ether fatty acid synthesis in late blight-diseased potato leaves. Plant Cell 11:485-493

35. Kolomiets MV, Hannapel DJ, Chen H, Tymeson M, Gladon RJ (2001) Lipoxygenase is involved in the control of potato tuber development. Plant Cell 13:613-626

36. Galliard T, Phillips DR (1972) The enzymic conversion of linoleic acid into 9-(nona-1', 3'-dienoxy)non-8-enoic acid, a novel unsaturated ether derivate isolated from homogenates of Solanum tuberosum tubers. Biochem J 129:743-753

37. Shimizu T, Radmark O, Samuelsson B (1984) Enzyme with dual lipoxygenase activities catalyses leukotriene A4 synthesis from arachidonic acid. Proc Natl Acad Sci USA 81:689-693

38. Regdel D, Kühn H, Schewe T (1994) On the reaction specificity of the lipoxygenase from tomato fruits. Biochim Biophys Acta 1210:297-302

39. Mulliez E, Leblanc J-P, Girerd J-J, Rigaud M, Chottard J-C (1987) 5-Lipoxygenase from potato tubers. Improved purification and physicochemical characteristics. Biochim Biophys Acta 916:13-23

40. van Aarle PGM, Debarse MMJ, Veldink GA, Vliegenthart JFG (1991) Purification of a lipoxygenase from ungerminated barley-characterization and product formation. FEBS Lett 280:159-162

41. Gardner HW (1989) Soybean lipoxygenase-1 enzymatically forms both $9(S)$ - and 13(S)-hydroperoxides from linoleic acid by a pH-dependent mechanism. Biochim Biophys Acta 1001:274281

42. Veldink G, Garssen GJ, Vliegenthart JFG, Boldingh J (1972) Positional specificity of corn germ lipoxygenase as a function of pH. Biochem Biophys Res Commun 47:22-26

43. Shibata D, Slusarenko A, Casey R, Hildebrand D, Bell E (1994) Lipoxygenases. Plant Mol Biol Rep 12:S41-S42 